\title{
Innovative procedure to produce high performance pretensioned concrete girders combining high strength concrete and normal or special concrete types
}

\author{
C. Vázquez-Herrero \& F. Martínez-Abella \\ Department of Construction Engineering, School of Civil Engineering, \\ University of La Coruña, Spain
}

\begin{abstract}
As is well known, prefabrication procedures allow significant reductions in construction time. In many countries, precast concrete bridges are customary and made up of pretensioned prestressed girders. Both the compressive and tensile strength of the concrete mix must be enough at transfer (which takes place typically two or three days after concrete casting) in order to avoid excessive prestress losses, and undesirable cracking. Many attempts have been made to increase the spectrum of the usual high performance concretes to other concrete types (i.e. normal strength concrete, lightweight concrete and recycled aggregate concrete). Why are these special concrete types not used in the current production of large pretensioned concrete girders? Technical problems have been observed at the critical zones: development length, geometrical discontinuities, supports, etc. A new technique has been developed by the authors to produce hybrid pretensioned concrete elements, combining the usual high strength concretes in the critical zones with other concrete types in the rest of the elements.

Keywords: prestressed concrete, precast concrete, pre-tensioning, pretensioned, pretensioned, high performance, high strength, prestressed, girders, beams.
\end{abstract}

\section{Introduction}

As is well known, the prefabrication procedures allow significant reductions in the construction time. In many countries precast concrete bridges are customary, made up of pretensioned prestressed girders deck. 
In post-tensioned structures, the transfer of prestress is done through mechanical anchorage. However, in pretensioned structures strand force is transmitted to concrete by bond, which is essential to:

- Transfer the prestressing force to the beam during the service life. Transfer length is defined (after Weerasekera [1]) as the distance over which the strand should be bonded to concrete in order to develop the effective prestress stress $\left(f_{p e}\right)$ in the strand (see Figure 1) .

- Guarantee the anchorage of the prestressing force. The flexural bond length is defined as the distance beyond the transfer length required to achieve the prestress design stress $\left(f_{p s}\right)$ during the service life (see Figure 1). The development length is the sum of the transfer length and the flexural bond length.

Accordingly two different zones are determined along these elements: the external zones, where the bearing capacity is lower than the design capacity (development length) and the inner zone, where prestress is fully effective.

Both the compressive and tensile strength of the concrete mix must be high enough at transfer (which takes place typically two or three days after concrete casting) in order to avoid excessive prestress losses, and undesirable cracking. The stresses created by bond in concrete are so high that the use of high strength concrete is usually required to prevent cracking along the transfer length.

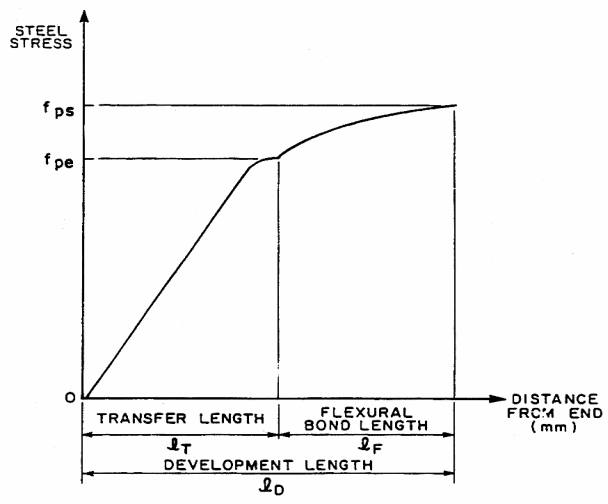

Figure 1: $\quad$ Transfer length and development length.

Many attempts were made to increase the spectrum of the conventional high performance concretes to other concrete types (i.e. moderate strength concrete, lightweight concrete and recycled aggregate concrete).

The use of lightweight concrete having similar strength compared to the current high strength concrete, would allow either the reduction of the self weight of these elements while maintaining their span length, or the increase of the span length while maintaining the self weight.

On the other hand, a reduction of the requirements of the resistant properties of concrete would imply a significant cost reduction. The use of normal strength 
concrete is desirable, instead of the current high strength concrete. However this possibility must be carefully studied, in order not to affect the performance of the structure during the service life.

Environmental regulations are hardening in developed countries. The extraction of aggregates is being penalized. In the future, a considerable increase of the cost of natural aggregates will be experienced. Consequently, the applicability of recycled aggregate concrete to the prefabrication processes must be studied.

Why are these special concrete types not used in the current production of large pretensioned concrete girders? In our opinion it is due to their high cost and eventually to the technical problems at the critical zones: development length, geometrical discontinuities, supports, etc.

Nowadays, the bearing capacity of the pretensioned concrete elements is limited by the feasibility of introducing the maximum prestress in the cross section due to the restrictions of minimum center-to-center strand distance as well as on minimum cover.

Several attempts to use high strength lightweight concrete instead of the current normal weight concrete, with the same design criteria have failed due to longitudinal cracking along the ends of the girders (Vázquez-Herrero and Martínez-Abella [2]). These cracks are generated by the high stresses in the boundary between strands and surrounding concrete:

- Normal stresses between strand and the surrounding concrete, caused by the recovery of the strand diameter after transfer. As a result transverse tensile stresses appear in the surrounding concrete (bursting stresses) along the whole length of the pretensioned concrete elements.

- Bond stresses along the transfer length. The resulting transverse stresses which appear in the surrounding concrete are named splitting stresses.

Longitudinal cracking along the pretensioned concrete elements is unacceptable, because it nullifies the protection against corrosion of the strand provided by concrete cover. So it is necessary to prevent this kind of damage.

The dispositions that have been usually considered in order to reduce the risk of longitudinal cracking are the following:

- Methods to enhance the confinement of the strands. With this aim transverse reinforcement is disposed, either through stirrups or spiral reinforcement. This procedure does not prevent cracking, but it certainly reduces crack width, and prevents losing the confining effect. These methods imply a considerable increase of operational costs.

- Methods to reduce bond between active reinforcement and concrete by different means, i.e.: reduction of the strand surface roughness, use of lubricating substances, use of partially debonded tendons, etc. An adverse effect is collateral to these measures: the increase of the development length means a reduction of the bearing capacity of the girders at this zone. Besides, it is difficult to exert and control the rate of bond reduction desired. 
In this paper an alternative procedure to produce pretensiond concrete elements, which allows the use of a normal strength concrete is presented. This is explained in the following section.

\section{A procedure to produce hybrid pretensioned concrete elements}

The scope of the procedure is to produce pretensioned concrete elements with what will be named objective concrete, which can be either a normal strength concrete or a special type of concrete (i.e. lightweight concrete, recycled aggregate concrete, fiber reinforced concrete, etc.).

The critical zones of the structure are determined by :

- The bending moments along the structure determine the situation of the zones where the prestressing force is not constant, which means the existence of bond stresses.

- The stress concentration zones, such as supports, holes, zones where the geometry changes abruptly,...

The objective concrete will be used in most of the concrete girders, but in the critical zones, which will be executed using a high strength concrete mix that has proved a good performance. The adequate performance of the objective concrete in the non critical zones must be checked experimentally, in order to determine the adequacy of the material for this use.

The production procedure is similar to current girders', but for the different phases, which will be determined by the different critical zones. The boundary surface between the different concrete types can be accomplished by the use of any kind of formwork, or by the natural slope adopted by concrete.

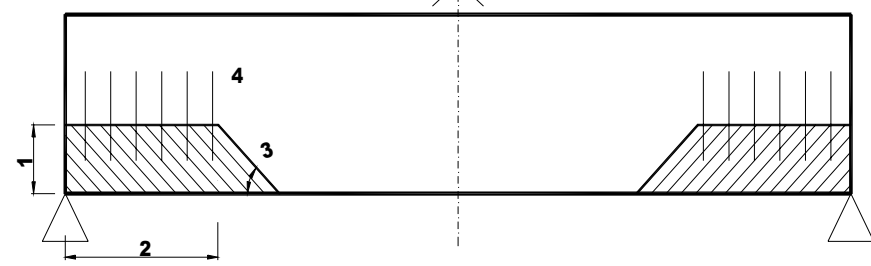

Figure 2: Hybrid pretensioned concrete girder.

Figure 2 presents an example of a simply supported beam, which will take part of an isostatic bridge with precast girders deck. The depth of the critical zone (see flag 1 in Figure 2) is determined by the upper strand level, adding the convenient cover. The critical zones are delimited by the development length of the lower tendons (see flag 2 in Figure 2). The adopted angle (see flag 3 in Figure 2) of the boundary must be fixed to completely define the critical zone. 
The reinforcement required to transmit the horizontal component of the shear stresses (see flag 4 in Figure 2) must be conveniently anchored at both sides of the interphase. The rest of the element is cast with the objective concrete.

\section{A procedure to assess the performance of hybrid pretensioned concrete elements}

In order to study the feasibility of producing hybrid pretensioned concrete beams, the folowing procedure is proposed:

1. Initially, several hybrid pretensioned concrete prisms must be produced and tested (see Figure 3). The critical zones have to be performed using a high strength concrete mix, and the rest using the objective concrete. These elements must be monitored for at least several months after transfer, to detect eventual cracking or unexpected growth of the transfer length.

2. If the behavior of the prisms is considered satisfactory, the second stage consists of producing at plant several hybrid pretensioned girders, these elements have to be monitored, and some of them tested to failure (see Figure 4) to estimate their bearing capacity and development length.

3. As a final stage of the design process, a prototype structure will be designed, built and monitored for several years. Only if this final stage is successful, current production of the hybrid pretensioned concrete elements can be attempted.

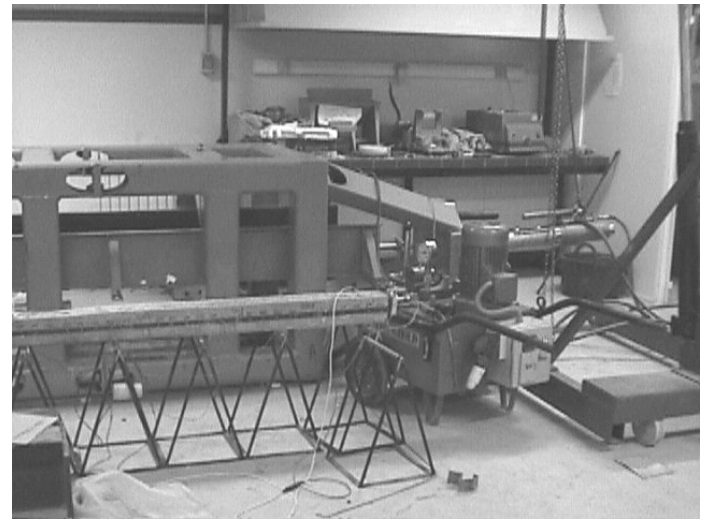

Figure 3: $\quad$ Pretensioning bench and hybrid pretensioned concrete prism. 


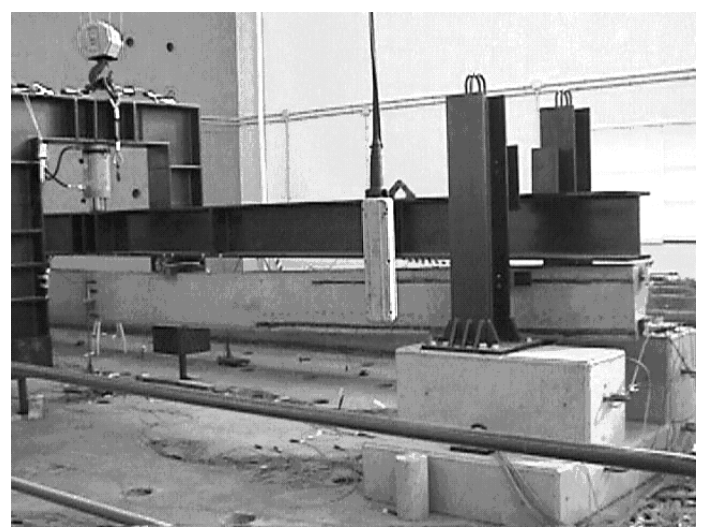

Figure 4: $\quad$ Flexural test on a pretensioned concrete girder.

\section{The behavior of hybrid pretensioned elements of lightweight concrete-high strength concrete}

An experimental research was planned to study the feasibility of producing pretensioned concrete elements with lightweight concrete (LC, see Table 1). The proposed LC mix contains expanded clay as lightweight aggregate. Previously an experimental research had been undertaken to study the feasibility of lightweight concrete pretensioned elements, but longitudinal cracking appeared at the transfer length regions of these elements some time after transfer (VázquezHerrero and Martínez-Abella [2]).

The pretensioned concrete prisms (square cross section $105 \mathrm{~mm}$ wide, 3750 $\mathrm{mm}$ long) were produced at the School of Engineering Laboratory, in a $4 \mathrm{~m}$ pretensioning bench designed for this research (see Figures 3 and 5). This part of the experimental research has been the subject of the undergraduate research project of Félix Sañudo-Herrera [3]. The critical zones (1500 $\mathrm{mm}$ long from the end of the elements) were cast with a high strength concrete (RC, see Table 1), and the inner part (750 $\mathrm{mm}$ long) was cast afterwards with the lightweight concrete mix.

Table 1: $\quad$ Properties of the concrete mixes.

\begin{tabular}{|l|c|c|c|c|c|c|c|}
\hline Prop. & $\begin{array}{c}\text { Concrete } \\
\text { specific } \\
\text { weight }\end{array}$ & $\begin{array}{c}\text { Average } \\
\text { concrete } \\
\text { cylinder } \\
\text { strength, at } \\
2 \text { days }\end{array}$ & $\begin{array}{c}\text { Average } \\
\text { split tensile } \\
\text { strength, at } \\
2 \text { days }\end{array}$ & $\begin{array}{c}\text { Average } \\
\text { modulus of } \\
\text { elasticity, at } \\
2 \text { days }\end{array}$ & $\begin{array}{c}\text { Average } \\
\text { direct } \\
\text { tensile } \\
\text { strength, at } \\
2 \text { days }\end{array}$ & $\begin{array}{c}\text { Average } \\
\text { concrete } \\
\text { cylinder } \\
\text { strength, at } \\
\text { 28 days }\end{array}$ & $\begin{array}{c}\text { Average } \\
\text { direct } \\
\text { tensile } \\
\text { strength, at } \\
28 \text { days }\end{array}$ \\
\hline UNITS & $\mathrm{KN} / \mathrm{m}^{3}$ & $\mathrm{MPa}$ & $\mathrm{MPa}$ & $\mathrm{MPa}$ & $\mathrm{MPa}$ & $\mathrm{MPa}$ & $\mathrm{MPa}$ \\
\hline RC & 22 & 50 & 3.2 & 30441 & 3.3 & 67 & $>3.3$ \\
\hline LC & 17 & 48 & 2.7 & 19939 & 2.7 & 56 & 2.9 \\
\hline
\end{tabular}


Strand type was Y1860 S7 (1860 MPa), with a diameter of $15.2 \mathrm{~mm}(0.6$ "). Strand was tensioned until a stress of $75 \%$ of the minimum ultimate stress was attained. From the stressing process to the prestress force release 48 hours elapsed. Transfer was performed through gradually by flame heating.

The prisms were continuously monitored during the transfer process and afterwards. Transfer length was measured periodically after transfer, and its values kept steady within the high strength concrete critical zones. The prisms did not show any visible cracking for several months, but after 3-5 months longitudinal cracks appeared along the lightweight concrete inner part of all the hybrid specimens. Cracks progressed throughout the whole lightweight concrete inner part.

Consequently, the tested lightweight concrete mix used is not able to withstand the bursting stresses resulting from the strand diameter recovery which takes place after transfer due to the Poisson effect. Although the performance of the hybrid prisms is adequate for the first several months after transfer, durability cannot be assessed throughout the whole service life of the structure.

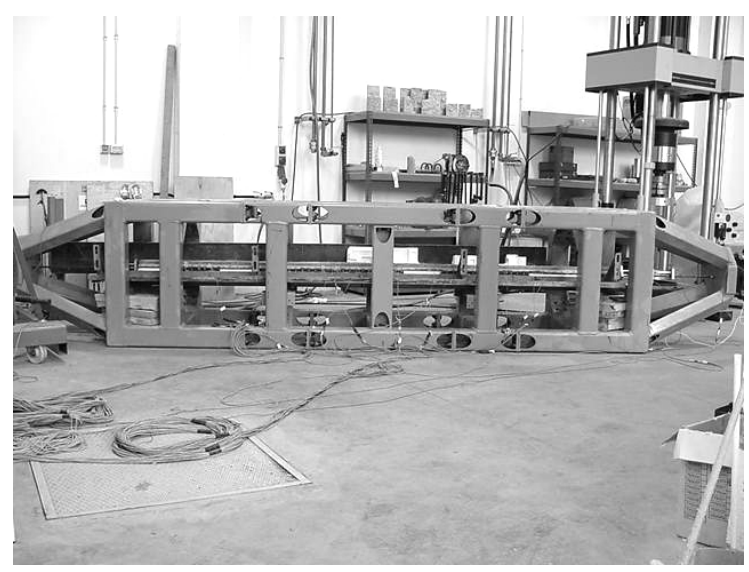

Figure 5: View of the pretensioning bench and the prism during testing.

\section{Conclusions}

After the experimental program carried out on hybrid pretensioned concrete elements, the following conclusions have been established:

- A procedure has been developed to design and produce hybrid pretensioned concrete elements (girders, beams, hollow core plates, etc.) using a given objective concrete in most parts of the element. The critical zones will be performed using a concrete mix that has shown a good performance (i.e. high strength concrete). Special attention must be paid to the design of the boundary surface between both concrete mixes. 
- An objective high strength lightweight concrete was tested, by means of producing hybrid pretensioned concrete prisms. This lightweight concrete mix is not adequate for the production of hybrid pretensioned concrete girders, using $15.2 \mathrm{~mm}$ diameter strand, with a cover of $50 \mathrm{~mm}$, measured from the strand center.

- The prism test has shown a good procedure to detect potential problems of the objective concrete, for a given strand size and cover. In our opinion this first stage is very convenient to study the feasibility of the proposed objective concrete mixes.

- In our opinion further research should be done using a stronger lightweight concrete aggregate, strong enough to restrain cracks propagation. Eventually the use of fiber reinforced concrete, either lightweight or normal weight concrete, is another way to increase concrete tensile strength.

Further research will be done at the University of La Coruña dealing with different objective concrete types (i.e. normal weight concrete of moderate strength, fiber reinforced concrete and recycled aggregate concrete) in order to widen the scope of pretensioned concrete elements.

\section{Acknowledgements}

This research project has been sponsored by the cement and concrete firm Corporación Noroeste, and by the projects XUGA22801A97 and CICYTMAT20001-0765 (Ministry of Science and Technology, Spain). The authors appreciate the contribution of the engineers Mr. Humberto Vázquez, Mr. Arturo Martínez, Mr. Marcos Fernández and Mr. Juan Rabuñal, and of Professor Dr. Pablo Rodríguez-Vellando for the revision of this text.

\section{References}

[1] Weerasekera, I.R., Transfer and Flexural Bond in Pretensioned Prestressed Concrete, PhD Thesis, UMI: Michigan, 1991.

[2] Vázquez-Herrero, C., Martínez-Abella, F., Bond Properties of High Strength Pretensioned Lightweight and Normal Weight Concrete, Proceedings of Bond in Concrete, Budapest, pp. 791-798, 2002.

[3] Sañudo-Herrera. F., Experimental study of the behavior of hybrid pretensioned concrete elements using high strength concrete and lightweight concrete, Undergraduate Research Project (in Spanish), University of La Coruña, 2003. 